\title{
Pembinaan dan Pengembangan Bahasa Daerah dalam Memantapkan Kedudukan dan Fungsi Bahasa Indonesia
}

\author{
Asrif*) \\ Pos-el: asrif_wakatobi@yahoo.co.id
}

\begin{abstract}
Abstrak
Bahasa daerah sebagai salah satu kekayaan bangsa memiliki fungsi sebagai alat komunikasi bagi masyarakat pendukungnya. Selain sebagai alat komunikasi intraetnik, bahasa daerah juga berfungsi sebagai pendukung bahasa nasional, yakni bahasa Indonesia. Atas dasar fungsi ini seharusnya bahasa daerah terus dibina dan dikembangkan dalam rangka memperkukuh ketahanan budaya bangsa. Bahasa daerah sebaiknya tidak lagi diperlakukan sebagai salah satu kebudayaan yang fungsinya dapat diganti oleh fungsi bahasa lain. Pasal 36 UUD 1945 menyebutkan, antara lain, bahwa bahasa daerah yang dipelihara dengan baik oleh para penuturnya akan dihormati dan dipelihara oleh negara karena bahasa-bahasa daerah tersebut merupakan sebagian dari kebudayaan Indonesia yang hidup. Kebijakan Bahasa Nasional merumuskan bahwa dalam hubungannya dengan perkembangan kehidupan kenegaraan di Indonesia ke arah pemerintahan otonomi daerah serta pentingnya pembinaan dan pelestarian budaya daerah, bahasa daerah perlu diberi kesempatan yang seluas-luasnya memainkan peranan yang lebih besar. Pemantapan keberadaan dan kesinambungan bahasa daerah bertujuan melindungi bahasa daerah yang merupakan salah satu kekayaan bangsa. Bahasa Indonesia sebagai bahasa yang dinamis dapat memanfaatkan kosakata bahasa daerah sebagai pemerkaya kosakata bahasa Indonesia. Sikap ini tidak hanya memantapkan kebudayaan daerah, tetapi juga memantapkan kebudayaan nasional.
\end{abstract}

Kata kunci: pembinaan, pengembangan, kedudukan, dan fungsi bahasa

\section{Pendahuluan}

Salah satu kekayaan bangsa Indonesia yang jarang dimiliki oleh bangsa-bangsa lain adalah terdapatnya aneka bahasa daerah yang hidup berdampingan dengan bahasa Indonesia. Keanekaan bahasa

\footnotetext{
*) Staf Teknis pada Kantor Bahasa Provinsi Sulawesi Tenggara
} 
daerah yang ada di Indonesia dapat menjadi potensi yang positif dalam mengembangkan dan mempermantap kedudukan bahasa nasional yakni bahasa Indonesia. Oleh karena itu, menjadi tidak bijak jika bahasa daerah dianggap sebagai bahasa 'pengganggu' bahasa Indonesia.

Bahasa daerah atau yang biasa juga disebut dengan bahasa etnis atau bahasa ibu telah menjadi agenda UNESCO dengan menetapkan tanggal 21 Februari sebagai Hari Bahasa Ibu Internasional. Oentarto Sindung Mawardi dalam makalahnya yang berjudul "Peran Bahasa dan Sastra Daerah dalam Memperkukuh Ketahanan Budaya Bangsa" (2003:5) mengatakan bahwa apa yang dilakukan oleh UNESCO di atas menunjukkan betapa pentingnya upaya mempertahankan pemakaian serta pemberdayaan fungsi bahasa daerah/etnis/bahasa ibu di tengah-tengah masyarakat pendukungnya.

\section{Pembahasan}

\subsection{Kedudukan dan Fungsi Bahasa Indonesia dan Bahasa Daerah}

\subsubsection{Bahasa Indonesia}

Dalam rumusan seminar politik bahasa disebutkan bahwa salah satu kedudukan bahasa Indonesia adalah sebagai bahasa persatuan atau bahasa nasional. Di dalam kedudukannya sebagai bahasa nasional, bahasa Indonesia berfungsi sebagai (1) lambang kebanggaan nasional, (2) lambang identitas nasional, (3) alat pemersatu berbagai etnik yang berbeda latar belakang sosial budaya dan bahasanya, dan (4) alat perhubungan antarbudaya serta antardaerah.

Kedudukan bahasa Indonesia sebagai bahasa nasional dengan berbagai fungsi seperti yang dikemukakan di atas dipermantap dengan menjadikan bahasa Indonesia sebagai bahasa negara. Kedudukan 
bahasa Indonesia sebagai bahasa negara tercantum dalam UUD 1945, Bab XV, Pasal 36 yang berbunyi Bahasa negara ialah bahasa Indonesia. Ketentuan yang menetapkan bahasa Indonesia sebagai bahasa negara disertai pula dengan rumusan mengenai beberapa fungsi bahasa Indonesia sebagai bahasa negara.

Bagaimana dengan bahasa daerah? Apakah negara memberi peluang kepada bahasa daerah untuk menjadi bahasa etnik dan memberi sumbangsih bagi perkembangan bahasa Indonesia? Berikut ini diuraikan kedudukan dan fungsi bahasa daerah sebagaimana rumusan seminar politik bahasa.

\subsubsection{Bahasa Daerah/Etnis}

Bahasa daerah yang ada di Indonesia yang jumlahnya sekitar 700 buah berfungsi sebagai (1) lambang kebanggaan daerah, (2) lambang identitas daerah, (3) alat perhubungan di dalam keluarga, (4) sarana pendukung budaya daerah dan bahasa Indonesia, serta (5) pendukung sastra daerah dan sastra Indonesia.

Dalam rumusan seminar politik bahasa tahun 1999, disepakati pula beberapa fungsi bahasa daerah dalam hubungannya dengan fungsi bahasa Indonesia sebagai bahasa nasional dan bahasa negara. Fungsi-fungsi bahasa daerah, yakni (1) pendukung bahasa Indonesia, (2) bahasa pengantar pada tingkat permulaan sekolah dasar di daerah tertentu untuk memperlancar pengajaran bahasa Indonesia dan/atau pelajaran lain, dan (3) sumber kebahasaan untuk memperkaya bahasa Indonesia. Ketiga fungsi bahasa daerah tersebut dilengkapi lagi dengan penjelasan bahwa dalam keadaan tertentu, bahasa daerah dapat juga berfungsi sebagai pelengkap bahasa Indonesia di dalam penyelenggaraan pemerintahan pada tingkat daerah. 
Kedudukan dan fungsi bahasa Indonesia dan bahasa daerah seperti yang dikemukakan di atas merupakan rumusan fungsi yang ideal bagi keberlangsungan hidup bahasa Indonesia dan bahasa daerah. Tersurat secara jelas bagaimana hubungan antara bahasa Indonesia sebagai bahasa nasional dan bahasa negara di satu pihak dan bahasa daerah sebagai bahasa etnis di pihak yang lain.

\subsection{Posisi Bahasa Indonesia dan Bahasa Daerah Saat Ini}

Saat ini, kedudukan dan fungsi bahasa Indonesia, baik sebagai bahasa nasional maupun sebagai bahasa negara telah terlaksana dengan baik. Bahasa Indonesia telah memerankan fungsinya sebagai lambang dan identitas nasional, alat pemersatu berbagai etnik, dan sebagai alat perhubungan antarbudaya. Bahasa Indonesia juga telah berfungsi sebagai bahasa resmi kenegaraan. Bagaimana dengan fungsi bahasa daerah?

Untuk mengetahui pelaksanaan fungsi bahasa daerah, sebaiknya kita menengok sejenak butir (4) fungsi bahasa daerah yang disebutkan bahwa bahasa daerah berfungsi sebagai sarana pendukung budaya daerah dan bahasa Indonesia. Di dalam hubungannya dengan fungsi bahasa Indonesia, pada butir (1) dinyatakan bahwa bahasa daerah berfungsi sebagai pendukung bahasa Indonesia, dan pada butir (3) dinyatakan bahwa bahasa daerah berfungsi sebagai sumber kebahasaan untuk memperkaya bahasa Indonesia.

Ketiga butir fungsi bahasa daerah di atas, secara tegas, memberi peluang kepada bahasa daerah untuk lebih berkembang dan dapat mendukung bahasa Indonesia. Bahasa daerah memiliki peluang memainkan peran yang lebih besar dalam memperkaya kosakata bahasa Indonesia. Namun, apakah fungsi bahasa daerah seperti yang 
tercantum dalam tiga butir rumusan fungsi bahasa daerah saat seminar politik bahasa tahun 1999 telah berjalan dengan baik?

Nababan (1990) dalam makalahnya yang berjudul "Kedwibahasaan dan Perkembangan Bahasa Indonesia dan Bahasa Daerah" melaporkan bahwa pada tahun 1980, Pusat Pembinaan dan Pengembangan Bahasa (sekarang bernama Pusat Bahasa) merencanakan penyelenggaraan suatu survei mengenai kedwibahasaan di Indonesia. Salah satu hasil atau kesimpulan survei tersebut yakni perubahan ke arah penggunaan bahasa Indonesia sebagai bahasa pertama kelihatan cukup jelas.

Hasil survei ini mengisyaratkan pada kita bahwa di beberapa daerah di Indonesia, mulai terjadi pergeseran pemakaian bahasa yang dari pemakaian bahasa daerah menjadi pemakaian bahasa Indonesia.

Pergeseran pemakaian bahasa dari bahasa daerah ke bahasa Indonesia menimbulkan pertanyaan. Masihkah fungsi bahasa daerah sebagai alat komunikasi etnik, sebagai pendukung bahasa Indonesia, dan sebagai sumber kosakata bahasa Indonesia, akan dilaksanakan oleh masyarakat Indonesia sebagaimana hasil rumusan seminar politik bahasa tahun 1999? Pertanyaan ini hadir sebagai akibat semakin menyusutnya wilayah pemakaian bahasa daerah, rusaknya tata bahasa daerah yang dipakai oleh para penutur muda, minimnya kosakata bahasa daerah yang terserap ke dalam kosakata baku bahasa Indonesia, dan acuh tak acuhnya pemerintah daerah dalam hal pelestarian bahasa daerah di wilayahnya.

Peralihan pemakaian bahasa ibu dari bahasa daerah menjadi bahasa Indonesia, kekacauan kosakata bahasa daerah (misalnya kosakata indorah: Indonesia-Daerah), terbatasnya jumlah kosakata bahasa daerah yang terserap ke dalam bahasa Indonesia, dan 
kekurangpedulian pemerintah daerah terhadap pelestarian bahasa daerah menunjukkan belum terlaksananya kedudukan dan fungsi bahasa daerah secara baik seperti yang terumus dalam seminar politik bahasa tahun 1999. Jika hal ini berlangsung secara terus menerus, maka tidak tertutup kemungkinan, rumusan kedudukan dan bahasa fungsi bahasa daerah hanyalah sebuah slogan yang setengah hati untuk dilaksanakan.

\subsection{Acuan Pembinaan dan Pengembangan Bahasa Daerah}

Pasal 32 Undang-Undang Dasar (UUD) 1945 Perubahan Keempat yang terdiri atas dua ayat berbunyi sebagai berikut.

Ayat (1) Negara memajukan kebudayaan nasional Indonesia di tengah peradaban dunia dengan menjamin kebebasan masyarakat dalam memelihara dan mengembangkan nilai-nilai budayanya.

ayat (2) Negara menghormati dan memelihara bahasa daerah sebagai kekayaan budaya nasional.

Kedua ayat yang tercantum dalam pasal 32 UUD 1945 Perubahan Keempat di atas menyatakan secara tegas kepada masyarakat Indonesia mengenai kedudukan bahasa daerah di Indonesia, siapa yang wajib memeliharanya, dan mengapa bahasa daerah patut dipelihara. Dalam dua ayat tersebut dikemukakan secara jelas hubungan bahasa daerah dengan budaya bangsa (budaya nasional) secara hukum (Bawa, 2003:2-3).

Pada pasal 32 ayat (1) dan (2), negara menyatakan bahwa bahasa daerah memiliki kedudukan yang sangat tinggi. Dalam kedudukannya yang sangat tinggi, bahasa daerah wajib dipelihara dan dikembangkan oleh negara. Tidak hanya itu, negara juga menyatakan 
bahwa bahasa daerah wajib dimajukan dan dihormati oleh negara. Kewajiban negara untuk menghormati, memelihara, mengembangkan, dan memajukan bahasa daerah merupakan bentuk tanggung jawab negara dalam menjaga dan melestarikan salah satu kebudayaan bangsa karena memelihara bahasa daerah berarti memajukan kebudayaan nasional seperti maksud pasal 32 UUD 1945 ayat (1) Perubahan Keempat.

Dalam pelaksanaannya di masyarakat, pembinaan dan pengembangan bahasa daerah diserahkan kepada Pemerintah Daerah (Kabupaten/Kota). Pengaturan pelaksanaan pembinaan dan pengembangan bahasa daerah telah ditetapkan dalam Undang-Undang Nomor 22 tahun 1999, Pasal 11 ayat (2) yang menyatakan bahwa yang wajib dilaksanakan Pemerintah Daerah Kabupaten dan Pemerintah Daerah Kota meliputi pekerjaan umum, kesehatan, pendidikan dan kebudayaan, pertanian, perhubungan, industri dan perdagangan, penanaman modal, lingkungan hidup, pertanahan, koperasi, dan tenaga kerja.

\subsection{Pembinaan dan Pengembangan Bahasa Daerah Menuju}

\section{Kemantapan Kedudukan dan Fungsi Bahasa Indonesia}

Pada paparan sebelumnya, telah disampaikan bahwa bahasa daerah memiliki posisi yang sangat penting bagi negeri ini. Dengan melihat pentingnya bahasa daerah dalam mendukung kebudayaan nasional, pemerintah dapat menempuh beberapa langkah dalam membina dan mengembangkan bahasa daerah, yakni:

(1) pemantapan keberlangsungan penggunaan bahasa daerah sebagai sarana pendukung budaya daerah dan budaya Indonesia; 
(2) pemantapan kedudukan bahasa daerah sebagai sumber kebahasaan dalam memperkaya bahasa Indonesia; dan

(3) peningkatan mutu bahasa daerah yang merupakan unsur utama kebudayaan daerah yang pada gilirannya menunjang kebudayaan nasional.

Ketiga langkah di atas merupakan upaya membina dan mengembangkan bahasa daerah karena bahasa daerah merupakan penyokong kebudayaan nasional (Indonesia). Pemantapan keberlangsungan bahasa daerah bertujuan memelihara dan melindungi bahasa daerah agar tetap lestari dalam masyarakat etnik di Indonesia. Perlindungan dan pemeliharaan bahasa daerah tidak hanya penting bagi keberlangsungan bahasa daerah tersebut, tetapi juga sangat berarti nilainya bagi keutuhan budaya nasional. Pemikiran seperti ini perlu ditelaah dengan baik untuk menghindari munculnya sikap pesimis masyarakat mengenai keseriusan pemerintah dalam melindungi kebudayaan daerah.

Langkah kedua yakni pemantapan kedudukan bahasa daerah sebagai sumber kebahasaan dalam memperkaya bahasa Indonesia. Langkah ini dapat berupa pengutamaan penyerapan bahasa daerah ke dalam bahasa baku bahasa Indonesia. Selama ini, ketika ada istilah asing yang tidak memiliki padanan dalam bahasa Indonesia, maka kita sering menyerap langsung atau dengan tata cara tertentu, istilah-istilah asing tersebut. Kita tidak atau kurang berupaya menyerap kosakata bahasa daerah yang ada di Indonesia sebagai padanan istilah asing tersebut. Beberapa ahli bahasa memberi alasan bahwa penyerapan istilah asing diperlukan karena bahasa daerah tidak memiliki bentuk padanan atas kata asing itu. Memang, jika kita mencari bentuk padanan yang sama persis, maka kita tidak akan menemukannya 
dalam bahasa daerah. Sebaiknya, kita dapat berbijak terhadap bahasa daerah, maksudnya adalah walaupun makna kosakata bahasa daerah tidak persis sama dengan istilah asing yang akan diserap, tetapi kita dapat menyepakati sebuah kosakata bahasa daerah sebagai padanan istilah asing Bukankah salah satu ciri bahasa itu adalah kesepakatan?

Langkah ketiga yakni peningkatan mutu bahasa daerah yang merupakan unsur utama kebudayaan daerah yang pada gilirannya menunjang kebudayaan nasional. Dalam langkah ini, bahasa daerah sebagai salah satu kebudayaan daerah yang mengisi kebudayaan nasional sebaiknya tetap dijadikan sebagai bahasa ibu atau bahasa utama dalam rumah tangga dan lingkungan pendidikan. Bahasa daerah sebaiknya tetap dipakai dalam lingkungan pendidikan mendampingi bahasa Indonesia. Tujuannya agar bahasa daerah kembali berprestise di mata masyarakat pendukungnya.

Terkait dengan pemakaian bahasa daerah di lingkungan pendidikan, kita dapat menelaah kembali maksud Mahsun dalam makalahnya yang disampaikan dalam seminar Politik Bahasa tahun 1999. Dalam makalahnya tersebut, Mahsun mempersoalkan butir kedua putusan Seminar Politik Bahasa Nasional 1975 mengenai fungsi bahasa daerah dalam hubungan bahasa tersebut dengan bahasa Indonesia. Ahli bahasa tersebut menilai putusan yang menyatakan bahwa bahasa daerah berfungsi sebagai bahasa pengantar di sekolah dasar di daerah tertentu pada tingkat permulaan untuk memperlancar pengajaran bahasa Indonesia dan mata pelajaran lain, dianggap telah membentuk persepsi peserta didik akan kurang pentingnya bahasa dan kultur yang mereka miliki yang terekam dalam bahasa ibu mereka.

Pendapat Mahsun di atas sebaiknya perlu dipertimbangkan dengan sebaik-baiknya karena jika butir kedua fungsi bahasa daerah 
sebagaimana rumusan Seminar Politik Bahasa Nasional 1975 diimplementasikan, maka tidak tertutup kemungkinan persepsi peserta didik tentang bahasa daerah sebagai bahasa yang kurang penting akan semakin menguat. Di samping itu, secara tidak langsung kebijakan itu dapat membentuk pola berpikir negatif penutur bahasa daerah terhadap bahasa ibunya dan sekaligus akan mengurangi kebanggaan mereka terhadap bahasa dan kulturnya (periksa Mahsun dalam Seminar Politik Bahasa, 2000:40).

Dalam konteks keindonesiaan, sebaiknya bahasa daerah diposisikan sebagai bahasa utama selain bahasa Indonesia. Bahasa daerah jangan lagi dipandang sebagai bahasa kedua karena hal itu dapat memicu sikap negatif masyarakat terhadap bahasa daerah. Kedudukan bahasa daerah sebagai lambang kebanggaan etnik akan sulit tercapai karena posisi bahasa daerah yang ditempatkan sebagai bahasa kedua.

Untuk menghindari terjadinya tampang tindih wilayah pemakaian antara bahasa Indonesia dan bahasa daerah, diperlukan suatu rumusan baru tentang fungsi dan kedudukan bahasa Indonesia dan bahasa daerah. Misalnya, jika dalam satu kelas semua siswanya berasal dari etnik dan pemakai bahasa daerah yang sama, maka bahasa daerah dapat dipakai sebagai bahasa pengantar untuk menyampaikan materi pelajaran. Dalam kondisi ini, pemakaian bahasa daerah sebagai bahasa pengantar di lembaga pendidikan tidak hanya terbatas pada kelas-kelas rendah saja, tetapi dapat dipakai di semua kelas yang siswanya berasal dari etnik yang sama atau berpenutur bahasa daerah yang sama.

Beberapa hasil penelitian mengenai pemakaian bahasa daerah sebagai bahasa pengantar di lembaga pendidikan menunjukkan bahwa 
pemakaian bahasa daerah di sekolah mampu memberi hasil pembelajaran yang positif. Hasil penelitian Freeman dan Freeman (1992, dalam Mahsun, 1999) menyimpulkan bahwa siswa yang belajar di sekolah-sekolah yang menggunakan bahasa ibu sebagai bahasa pengantar, cenderung tidak mengalami kesulitan dalam mengikuti kegiatan belajar-mengajar yang menggunakan bahasa pengantar bahasa kedua. UNESCO dalam simpulan hasil penelitiannya menunjukkan bahwa pendidikan yang menggunakan bahasa ibu sebagai bahasa pengantar lebih berhasil jika dibandingkan dengan pendidikan yang tidak menggunakan bahasa ibu sebagai bahasa pengantar (dalam Fadjar, 2003:7).

Harapan agar bahasa daerah dijadikan sebagai bahasa utama di lembaga pendidikan selain bahasa Indonesia tidak bertujuan mengingkari bahasa Indonesia sebagai bahasa nasional dan bahasa negara. Bukan pula merupakan langkah pelegitimasian keberadaan bahasa daerah secara berlebihan. Akan tetapi, pemberdayaan bahasa daerah pada beberapa situasi justru bertujuan menguatkan semangat keindonesiaan. Indonesia sebagai sebuah negeri dibangun dari berbagai macam budaya semua etnik yang ada di kepulauan nusantara. Oleh karena itu, pemakaian atau dapat disebut pemberdayaan bahasa daerah sebaiknya dinilai sebagai upaya mempertahankan pilar-pilar budaya yang membangun negeri ini, Indonesia.

\section{Penutup}

Keanekaragaman bahasa daerah yang dimiliki Indonesia dapat digunakan secara berdampingan dengan bahasa Indonesia. Bahasa daerah dan bahasa Indonesia dapat saling mengisi sehingga 
semangat keindonesiaan yang menjadi pemerkukuh persatuan dan kesatuan bangsa akan semakin mantap.

Pembinaan dan pengembangan bahasa daerah merupakan suatu cerminan upaya untuk mendorong kemajuan daerah yang tidak saja melalui pembangunan ekonomi dan fisik daerah, melainkan juga pembangunan sosial budaya serta nilai-nilai luhur yang dikandungnya. Hal ini sesuai dengan falsafah pembangunan nasional kita dengan tujuan menciptakan suatu masyarakat yang tangguh menghadapi berbagai ancaman, tantangan, dan hambatan dalam mencapai tujuan berbangsa dan bernegara.

Pembinaan dan pengembangan bahasa daerah sebagai bentuk perwujudan semangat keindonesiaan tidak harus menggeser posisi bahasa Indonesia sebagai bahasa nasional dan bahasa negara. Pembinaan dan pengembangan bahasa daerah diarahkan pada pemberdayaan bahasa daerah (bahasa etnik) yang lebih mantap yang memiliki hubungan harmonis dengan bahasa nasional (bahasa Indonesia). Pemantapan kedudukan dan fungsi bahasa daerah yang diimplementasikan dalam kehidupan sehari-hari, sesungguhnya merupakan bentuk perwujudan semangat keindonesiaan pada sebuah negara yang sangat menghargai kebhinekaan yang tunggal ika. 


\section{Daftar Pustaka}

Alwi, Hasan dan Dendy Sugono (ed). 2000. Politik Bahasa. Jakarta: Pusat Bahasa, Departemen Pendidikan Nasional.

Anonim. 2002. Undang-Undang Dasar Tahun 1945. Surabaya: Pustaka Tama.

Bawa, I Wayan. 2003. "Perkukuh Budaya Bangsa dengan Memantapkan Peran Bahasa Daerah”. Makalah disampaikan dalam Kongres Bahasa Indonesia (KBI) VIII yang diselenggarakan oleh Pusat Bahasa, Departemen Pendidikan Nasional. Jakarta: Pusat Bahasa.

Fadjar, A. Malik. 2003. "Bahasa Indonesia, Pendidikan Nasional, dan Kehidupan Berbangsa”. Makalah disampaikan dalam Kongres Bahasa Indonesia (KBI) VIII yang diselenggarakan oleh Pusat Bahasa, Departemen Pendidikan Nasional. Jakarta: Pusat Bahasa.

Mahsun. 1999. "Bahasa Daerah sebagai Sarana Peningkatan Pemahaman Kondisi Kebhinekaan dalam Ketunggalikaan Masyarakat Indonesia ke Arah Pemikiran dalam Mereposisi Fungsi Bahasa Daerah", dalam Hasan Alwi dan Dendy Sugono (ed). Risalah Seminar Politik Bahasa. Jakarta: Pusat Bahasa.

Mawardi, Oentarto Sindung. 2003. "Peran Bahasa dan Sastra Daerah dalam Memperkukuh Ketahanan Budaya Bangsa”. Makalah disampaikan dalam Kongres Bahasa Indonesia (KBI) VIII yang diselenggarakan oleh Pusat Bahasa, Departemen Pendidikan Nasional. Jakarta: Pusat Bahasa.

Nababan, P.W.J. 1990. "Kedwibahasaan dan Perkembangan Bahasa Indonesia dan Bahasa Daerah", dalam Husen Abas dan T. David Andersen (penyunting). Prosiding Konferensi dan Seminar Nasional Ke-5 Masyarakat Linguistik Indonesia: Bahasa-Bahasa Daerah Sulawesi dalam Konteks Bahasa Nasional. Ujung Pandang: Unhas-SIL. 